JMK: JURNAL MEDIA KESEHATAN

P-ISSN : 1979-5750

E-ISSN: 2654-5705

\title{
TINGKAT PENGETAHUAN TENTANG MENOPAUSE DENGAN KUALITAS HIDUP WANITA PERIMENOPAUSE DI DESA SAKTI KECAMATAN NUSA PENIDA
}

\author{
Ni Komang Sri Ariani ${ }^{1)}$, Ni Made Ayu Yulia Raswati Teja ${ }^{1)}$ \\ ${ }^{1}$ Profesi Bidan, ITEKES Bali, Jln Tukad Balian No.180 Renon, Denpasar Bali, 80226 \\ mangsriex@gmail.com
}

\begin{abstract}
Every complaint experienced by menopausal women can cause decreased quality of life. Quality of life is a unique individual perception of dignity and value in the context of culture and value systems, in which individuals exist and are associated with life goals and individual targets. This situation is a description of satisfaction, a sense of well-being, compared to an ideal state or one that should be achieved and reflected in daily activities. The quality of life for menopausal women decreases because menopausal women are not ready to accept menopause. Objectives: to find out whether there is a relationship between the level of knowledge about menopause and the quality of life of perimenopausal women in Sakti Village, Nusa Penida District. Methods: This research is a descriptive analytic study with a cross sectional approach, a sample of 100 respondents who met the inclusion criteria. Results: Most of the level of knowledge possessed by perimenopausal women in Sakti Nusa Penida Village have a good level of knowledge (54\%) about menopause, while the quality of life of perimenopausal women in Sakti Village is good, namely 55\%. The results of the cross tabulation of the data show that most of the respondents who have a good level of knowledge, namely $31(31 \%)$ people, have a good quality of life too. Meanwhile, $22(22 \%)$ perimenopausal mothers who had less knowledge had a poor quality of life. Meanwhile, the results of hypothesis testing obtained a sig value of 0.600 (sig> 0.05). This means that there is no significant relationship between the level of knowledge and the quality of life of perimenopausal women in Sakti Village, Nusa Penida District.
\end{abstract}

Keywords: Knowledge Level, Quality of Life, Perimenopausal Women

\begin{abstract}
ABSTRAK
Pendahuluan: Setiap keluhan yang dialami wanita menopause, dapat menyebabkan kualitas hidup menurun. Kualitas hidup adalah suatu persepsi individual yang unik tentang harkat dan martabatnya di dalam konteks budaya dan sistem nilai, dimana individu berada serta berhubungan dengan tujuan hidup dan target individu. Keadaan tersebut sebagai gambaran dari kepuasan, rasa sejahtera, dibanding dengan keadaan ideal atau yang seharusnya bisa dicapai dan direfleksikan dalam aktifitas sehari-hari. Kualitas hidup wanita menopause menurun disebabkan karena wanita menopause belum siap menerima masa menopause tersebut. Tujuan penelitian: untuk mengetahui apakah ada hubungan tingkat pengetahuan tentang menopause terhadap kualitas hidup wanita perimenopause di Desa Sakti Kecamatan Nusa Penida Bali. Metode: deskriptif analitik dengan pendekatan cross sectional, sampel berjumlah 100 responden yang memenuhi kriteria inklusi. Hasil: Tingkat pengetahuan yang dimiliki wanita perimenopause di Desa Sakti Nusa Penida sebagian besar memiliki tingkat pengetahuan yang baik (54\%) mengenai menopause, sedangkan kualitas hidup yang dimiliki wanita perimenopause di Desa Sakti adalah baik yaitu sebesar 55\%. Hasil tabulasi silang data menunjukkan sebagian besar responden yang memiliki tingkat pengetahuan yang baik yaitu $31(31 \%)$ orang, mempunyai kualitas hidup yang baik juga. Sementara $22(22 \%)$ ibu perimenopause yang memiliki tingkat pengetahuan kurang mengalami mempunyai kualitas hidup yang kurang. Sementara itu, hasil pengujian hipotesis memperoleh nilai sig yaitu 0,600 ( $\mathrm{sig}>0,05)$. Ini berarti tidak ada hubungan yang bermakna antara tingkat pengetahuan dengan kualitas hidup wanita perimenopause di Desa Sakti Kecamatan Nusa Penida.
\end{abstract}

Kata Kunci: Tingkat Pengetahuan, Kualitas Hidup, Wanita Perimenopause 


\section{PENDAHULUAN}

Wanita yang mengalami menopause, baik menopause dini, perimenopause dan pasca menopause akan mengalami gejala klimakterium serta mempunyai masa transisi atau masa peralihan (Parsa, 2017). Periode klimakterium ini ditandai dengan rasa panas, haid tidak teratur, jantung berdebar dan nyeri saat buang air kecil, hal ini disebabkan akibat produksi hormon dari ovarium berkurang, masa menstruasi menjadi tidak teratur dan kemudian tidak menstruasi kembali (Parsa, 2017). Perubahan fisik pada tahap perimenopause terjadi pula pergeseran dalam kehidupan psikis pribadi, hal tersebut tentunya akan semakin memperbesar terjadinya sindrom perimenopause (Anwar, 2017).

Wanita menopause mengalami keluhan yang berbeda dan setiap keluhan menopause memiliki efek pada kualitas hidup wanita menopause, $80 \%$ wanita melaporkan keluhan yang tidak menyenangkan ketika menjelang menopause, seperti sakit kepala, masalah seksual, takikardi, hot flushes dan insomnia yang secara signifikan dapat mengurangi kualitas hidup wanita menopause (Astari, 2015). Gejala vasomotor (hot flushes, berkeringat di malam hari dan gangguan tidur) adalah gejala yang yang sering dialami oleh wanita menopause. Sekitar 70\% wanita mengalami hot flushes dan 30\% sampai $40 \%$ mengalami gangguan tidur (Suheimi, 2016). Gejala vasomotor dapat mempengaruhi kualitas hidup, mengganggu aktifitas kerja serta memperburuk kecemasan dan depresi (Thurston, 2012).

Setiap keluhan yang dialami wanita menopause, dapat menyebabkan kualitas hidup menurun. Kualitas hidup adalah suatu persepsi individual yang unik tentang harkat dan martabatnya di dalam konteks budaya dan sistem nilai, dimana individu berada serta berhubungan dengan tujuan hidup dan target individu. Keadaan tersebut sebagai gambaran dari kepuasan, rasa sejahtera, dibanding dengan keadaan ideal atau yang seharusnya bisa dicapai dan direfleksikan dalam aktifitas sehari-hari. Kualitas hidup wanita menopause menurun disebabkan karena wanita menopause belum siap menerima masa menopause tersebut (Ayers, 2013).

Survei pendahuluan yang dilakukan di Dusun Sebunibus, Desa Sakti, Kecamatan Nusa Penida, didapatkan 8 dari 15 orang wanita perimenopause yang tidak memahami tentang perubahan masa menopause. Dapat disimpulkan bahwa pengetahuan wanita perimenopause 
terhadap perubahan masa menopause kurang. Berdasarkan uraian tersebut maka penulis tertarik untuk meneliti hubungan tingkat pengetahuan tentang menopause dengan kualitas hidup wanita perimenopause di Desa Sakti Kecamatan Nusa Penida Adapun tujuan penelitian ini adalah untuk mengetahui hubungan tingkat pengetahuan tentang menopause dengan kualitas hidup wanita perimenopause.

\section{METODE PENELITIAN}

Jenis penelitian ini menggunakan desain penelitian deskriptif analitik dengan rancangan cross sectional. Penelitian ini dilakukan di Desa Sakti Kecamatan Nusa Penida yang dilakukan pada bulan Agustus-September 2020. Cara pengambilan sampel dalam penelitian ini menggunakan stratified random sampling. Besar sampel pada penelitian ini dihitung berdasarkan rumus perhitungan sample size dengan menggunakan hypothesis test for two population proportions (two-sides test), maka besar sampelnya adalah 100 orang. Penelitian ini telah mendapatkan persetujuan oleh Ketua Komisi Etik Penelitian Institut Teknologi dan Kesehatan Bali dengan no seri 03.0051/KEPITEKES-BALI/VIII/2020. Penelitian ini juga telah mendapatkan persetujuan dari Dinas Penanaman Modal dan Pelayanan Terpadu satu Pintu Pemerintah Provinsi Bali dengan no seri 070/11096/Izin C/DISPMPT. Setelah kedua ijin didapatkan, peneliti kemudian langsung melakukan pengumpulan data. Metode yang dilakukan dalam pengumpulan data adalah peneliti menyebarkan kuesioner melalui google form kepada ibu-ibu di Desa Sakti Kecamatan Nusa Penida yang sesuai dengan kriteria inklusi. Semua calon partisipan telah diberikan penjelasan mengenai maksud dan tujuan penelitian dan bersedia menjadi partisipan dalam penelitian.

Proses menjawab kuesioner dalam penelitian ini berlangsung kurang lebih 30 menit. Setelah Partisipan menjawab kuesioner penelitian, pastisipan mendapatkan kenangkenangan sebagai tanda ucapan terima kasih karena telah ikut serta dalam penelitian. Selain Partisipan, orang lain atau siapapun tidak boleh ikut memberikan sumbangan jawaban kepada responden demi untuk menghasilkan jawaban yang benar. Semua proses pengumpulan data ini dilaksanakan pada bulan September tahun 2020. 


\section{HASIL DAN PEMBAHASAN}

Penelitian ini dilakukan di 3 banjar di Desa Sakti Kecamatan Nusa Penida Kabupaten Klungkung dengan jumlah responden pada penelitian ini adalah 100 wanita perimenopause. Gambaran karakteristik wanita perimenopause di Desa Sakti dijabarkan berdasarkan umur, pendidikan, pekerjaan dan penghasilan. Karakteristik responden disajikan dalam Tabel 1

\section{Tabel 1 Karakteristik Responden di Desa Sakti}

\begin{tabular}{lcc}
\hline Karakteristik responden & n & \% \\
\hline Umur & & \\
$40-45$ & 54 & $54 \%$ \\
$46-50$ & 46 & $46 \%$ \\
Pendidikan & 5 & \\
$\quad$ SD & 12 & $5 \%$ \\
SMP & 46 & $12 \%$ \\
SMA & 37 & $46 \%$ \\
Akademi / PT & & $37 \%$ \\
Pekerjaan & 10 & \\
$\quad$ IRT & 63 & $10 \%$ \\
Buruh/Swasta/Wiraswasta & 27 & $63 \%$ \\
PNS & & $27 \%$ \\
Pendapatan Keluarga & 14 & $14 \%$ \\
$\quad$ Rendah (<Rp. 3.500.000) & 86 & $86 \%$ \\
Tinggi ( $\geq$ Rp.3.500.000) & $\mathbf{1 0 0}$ & $\mathbf{1 0 0 \%}$ \\
\hline Total & & \\
\hline
\end{tabular}

Berdasarkan distribusi frekuensi karakteristik wanita menjelang menopause di Desa Sakti sebagian besar wanita menopause memiliki umur 40-45 tahun yaitu sebanyak 54\%, sebagian besar wanita menopause memiliki Pendidikan Terakhir di tingkat Sekolah Menengah Atas yaitu sebesar 46\%. Pekerjaan terbanyak pada responden yaitu sebagai buruh/swasta/wiraswasta sebanyak 63\% serta sebagian besar memiliki penghasilan keluarga $\geq$ Rp. 3.500 .000 yaitu sebesar $86 \%$. 
Tabel 2 Deskripsi Pengetahuan dan Kualitas Hidup Wanita Menjelang Menopause

\begin{tabular}{lcc}
\hline \multicolumn{1}{c}{ Variabel } & n & $\%$ \\
\hline Pengetahuan & & \\
Baik & 54 & $54 \%$ \\
Kurang & 46 & $46 \%$ \\
\hline Kualitas Hidup & & \\
\hline Baik & 55 & $55 \%$ \\
Kurang & 45 & $45 \%$ \\
\hline TOTAL & $\mathbf{1 0 0}$ & $\mathbf{1 0 0 \%}$ \\
\hline
\end{tabular}

Tabel 2 menunjukan rata-rata tingkat pengetahuan yang dimiliki wanita perimenopause di Desa Sakti Nusa Penida sebagian besar memiliki tingkat pengetahuan yang baik (54\%) mengenai menopause. Tabel diatas juga menunjukan rata-rata kualitas hidup yang dimiliki wanita perimenopause di Desa Sakti adalah baik yaitu sebesar 55\%.

Tabel 3 Hubungan Tingkat Pengetahuan tentang Menopause dengan Kualitas Hidup Wanita Perimenopause

\begin{tabular}{lcccc}
\hline & \multicolumn{2}{c}{ Kualitas Hidup } & Total & Sig \\
\hline Tingkat Pengetahuan & Kurang & Baik & & \\
\hline Kurang & 22 & 24 & 46 & 0,600 \\
Baik & 23 & 31 & 54 & \\
\hline TOTAL & $\mathbf{4 5}$ & $\mathbf{5 5}$ & $\mathbf{1 0 0}$ & \\
\hline
\end{tabular}

Hasil tabulasi silang data menunjukkan sebagian besar responden yang memiliki tingkat pengetahuan yang baik yaitu 31 (31\%) orang, mempunyai kualitas hidup yang baik juga. Sementara $22(22 \%)$ ibu perimenopause yang memiliki tingkat pengetahuan kurang mengalami mempunyai kualitas hidup yang kurang. Sementara itu, hasil pengujian hipotesis memperoleh nilai sig yaitu 0,600 (sig > 0,05). Ini berarti tidak ada hubungan yang bermakna antara tingkat pengetahuan dengan kualitas hidup wanita perimenopause di Desa Sakti Kecamatan Nusa Penida. Ada banyak faktor yang dapat mempengaruhi kualitas hidup 
antara lain: status pernikahan, pendidikan, penghasilan, status pekerjaan, asuransi kesehatan, nilai dan kepercayaan keluarga dan pasangannya, jenis kelamin, umur, etnis ras dan faktor kesehatan (Ayers, 2013).

Hasil penelitian ini sejalan dengan penelitian yang dilakukan oleh Pertikasari, hasil penelitian tersebut mengemukakan pendidikan tidak mempengaruhi sikap wanita dalam menghadapi menopause, sedangkan usia mempengaruhi sikap wanita dalam menghadapi menopause. Wanita menopause mengalami keluhan yang berbeda dan setiap keluhan menopause memiliki efek pada kualitas hidup wanita menopause (Pertikasari, 2004).

Perimenopause mengacu pada waktu menjelang menopause ketika seorang wanita mulai mengalami perubahan siklus menstruasi seperti menstruasi yang tidak teratur atau perubahan aliran, siklus bisa lebih pendek atau lebih panjang. Beberapa wanita dapat mengalami gejala menopause selama 4-8 tahun sebelum siklus menstruasi terakhir, tidak ada cara untuk memprediksi berapa lama gejala menopause akan dimulai atau berapa lama akan bertahan (Herawati, 2012).

Pada penelitian ini pengetahuan diukur menggunakan kuesioner, dimana kuesioner pengetahuan mencakup pengertian, waktu terjadinya menopause serta tanda gejala menopause. responden yang memiliki pengetahuan yang baik disebabkan karena responden sudah melewati masa menopause, pengalaman yang telah dilewati oleh responden menyebabkan responden menjawab pernyataan pengetahuan berdasarkan pengalaman yang telah dilewati khususnya pada tanda gejala menopause serta usia menopause. Hal ini sesuai dengan teori yang menyatakan bahwa pengetahuan dibagi menjadi enam, tingkatan pertama adalah tahu yang diartikan sebagai recall atau memanggil memori yang telah ada sebelumnya Notoatmodjo (2010). 


\section{KESIMPULAN}

Tidak ada hubungan yang bermakna antara tingkat pengetahuan tentang menopause dengan kualitas hidup wanita perimenopause di Desa Sakti Kecamatan Nusa Penida dengan besarnya $\mathrm{p}=0,600$. Ada banyak faktor yang dapat mempengaruhi kualitas hidup wanita perimenopause antara lain: status pernikahan, pendidikan, penghasilan, status pekerjaan, asuransi kesehatan, nilai dan kepercayaan keluarga dan pasangannya, jenis kelamin, umur, etnis ras dan faktor kesehatan.

\section{UCAPAN TERIMA KASIH}

1. Ketua YPPLPK Bali yang telah memberikan support moril maupun materiil sebelum, selama dan setelah proses penyusunan laporan penelitian ini.

2. Rektor ITEKES Bali atas dukungan moril serta masukannya, baik yang bersifat teknis maupun administrasi.

3. Kepala Lembaga Penelitian dan Pengabdian kepada Masyarakat ITEKES Bali atas segala masukannya sehingga proses penyusunan laporan ini berjalan dengan lancar.

4. Rekan-rekan dosen dan semua pihak yang tidak dapat penulis sebutkan satu persatu atas kerjasamanya sehingga proses dan penyusunan laporan penelitian ini berjalan dengan lancar.

\section{DAFTAR PUSTAKA}

Anwar R, Judistiani RTD, Madjid TH, Abdurahman M. 2017. Modul Konseling Asuhan Kebidanan pada ibu Menopause. Jakarta: Sagung Seto; p. 45-63

Astari RY, Tarawan VM, Sekarwana N. 2015. Hubungan Antara Sindrom Menopause Dengan Kualitas Hidup Perempuan Menopause Di Puskesmas Sukahaji Kabupaten Majalengka. Buletin Penelitian Kesehatan; 42(3 Sep):171-84.

Australian Menopause Society. Diagnosing menopause. Jan 2016. Diunduh pada 17 Oktober 2018. Tersedia dari: www.menopause.org.au

Ayers B, Hunter M. 2013. Health-related quality of life of women with menopausal hot flushes and night sweats. Climacteric; 16(2):235-9

Group W. 2014. Development of the World Health Organization WHOQOL-BREF quality of life assessment. Psychological medicine. 1998; 28(3):551-8.Shifren JL, Gass ML, Group NRfCCoMWW. The North American Menopause Society recommendations for clinical care of midlife women. Menopause; 21(10):1038-62 
Herawati R. 2012. Faktor-faktor yang berhubungan dengan usia menopause di empat posyandu lansia wilayah kerja Puskesmas Rambah Kabupaten Rokan Hulu: Jurnal Maternal dan Neonatal. Jurnal Maternal dan Neonatal; 1(1).

Hidayat, AA. 2014. Metode Penelitian Keperawatan dan Teknis Analisis Data. Jakarta : Salemba

Keputusan Menteri Kesehatan Republik Indonesia Nomor 229/MENKES/SK/II/2010 Tentang Pedoman Asuhan Kebidanan Masa Menopause. Diunduh pada 7 januari 2016. Tersedia dari: www.depkes.go.id

Kumalasari F. 2014. Sikap Wanita Menopause Tentang Perubahan Pada Masa Menopause di Desa Gayaman Kecamatan Mojoanyar Kabupaten Mojokerto.

Moustafa M, Ali R, Taha SM. 2015. Impact of menopausal symptoms on quality of life among women's in Qena City. Egyptian Journal of Nursing; 10(1)

Notoadmojo, S. 2013. Pendidikan dan Perilaku Kesehatan. Jakarta : Rineka cipta

Notoatmodjo,S. 2010. Promosi Kesehatan Teori dan Aplikasi. Jakarta:Rineka Cipta

Parsa P, Tabesh RA, Soltani F, Karami M. Effect of group counseling on quality of life among postmenopausal women in Hamadan, Iran. Journal of menopausal medicine. $2017 ; 23(1): 49-55$

Pertikasari, S \& Hidajah, A.C., 2004. Pengaruh Umur, Status Perkawinan, Pendidikan, Pekerjaan, Dan Pengetahuan Terhadap Sikap Wanita Dalam Menghadapi Menopause. http://i-lib.ugm.ac.id/jurnal/detail.php?dataId=8721

Pusat Data dan Informasi Kementerian Kesehatan RI. Situasi Lanjut Usia (LANSIA) di Indonesia. [database on the Internet] 2015. Available from: http://www.depkes.go.id/resources/download/pusdatin/infodatin/infodatin\%20lansia \%202016.pdf.

Sugiyono. 2014. Metode Penelitian Pendidikan Pendekatan Kuantitatif, Kualitatif, dan R \& D. Bandung : Tarate

Suheimi, H. 2016. Pola Hidup untuk Meningkatkan Kualitas Wanita Menopause. Indonesian Journal of Obstetrics and Gynecology.

Thurston RC ea. Are vasomotor symptoms associated with sleep characteristics among symptomatic midlife women? Comparisons of self-reportand objective measures. NIH Public Acces. Menopause. 2012 (july;19(7):742-74)

Wahyuningsih A, Arisandi DP. Upaya Pencegahan Sindrom Pra Menopause Pada Wanita Pra Menopause. Jurnal Penelitian Keperawatan. 2016; 2(1) 